(2) Open Access Full Text Article

\title{
Prevalence and Factors Associated with Fear of COVID-I9 Among Homeless Individuals During the COVID-I 9 Pandemic: Evidence from the Hamburg Survey of Homeless Individuals
}

\author{
André Hajek (iD)' \\ Franziska Bertram (iD) ${ }^{2}$ \\ Victoria van Rüth ${ }^{2}$ \\ Benedikt Kretzler ${ }^{\prime}$ \\ Klaus Püschel ${ }^{2}$ \\ Fabian Heinrich ${ }^{2}$,* \\ Hans-Helmut König (D) ${ }^{1} *$ \\ 'Department of Health Economics and \\ Health Services Research, University \\ Medical Center Hamburg-Eppendorf, \\ Hamburg Center for Health Economics, \\ Hamburg, Germany; ${ }^{2}$ Department of \\ Legal Medicine, University Medical \\ Center Hamburg-Eppendorf, Hamburg, \\ Germany
}

*These authors contributed equally to this work

\begin{abstract}
Purpose: To clarify the prevalence and determinants of fear of COVID-19 among homeless individuals during the COVID-19 pandemic.

Patients and Methods: Data were taken from the Hamburg survey of homeless individuals ( $\mathrm{n}=150)$ covering homeless adults in Hamburg, Germany. Multiple linear regressions were used. Beyond sociodemographic and lifestyle-related independent variables, COVID-19related factors were also used as independent variables.

Results: In sum, $56.2 \%$ of homeless individuals reported no fear of COVID-19, 23.8\% reported a little fear of COVID-19, 9.2\% reported some fear of COVID-19 and 10.8\% reported severe fear of COVID-19. Regressions showed that an increased fear of COVID19 was significantly associated with younger age $(\beta=-.01, p<0.05)$, absence of chronic alcohol consume $(\beta=-.55, \mathrm{p}<0.01)$, an increased perceived own risk of getting infected with the coronavirus one day $(\beta=0.42, \mathrm{p}<0.001)$ and a higher agreement that a diagnosis of the coronavirus would ruin his/her life $(\beta=0.13, \mathrm{p}<0.01)$.

Conclusion: Given the poor hygienic conditions and their increased vulnerability, data surprisingly suggest a quite low fear of COVID-19 among homeless individuals. Efforts may be beneficial which contribute to thinking rationally about COVID-19 among homeless people, since low levels of fear of COVID-19 may contribute to careless behavior and can lead to super-spreading events.
\end{abstract}

Keywords: homeless, fear of COVID-19, COVID-19 worry, anxiety of COVID-19, SARS-CoV-2, coronavirus, alcohol

\section{Introduction}

According to the Federal Association for Assistance to Homeless People (BAGW) slightly less than 680,000 homeless individuals lived in Germany in $2018{ }^{1}$ and about 6600 homeless individuals lived in Hamburg in $2018,{ }^{2}$ the second largest city in Germany. Compared to the general population, homeless individuals have higher prevalence rates of, among other things, mental disorders and infectious diseases such as HIV or tuberculosis. Furthermore, homelessness is associated with mortality. ${ }^{3}$ It is worth noting that the number of homeless individuals increased in the past years ${ }^{1}$ highlighting the importance of this group.

In light of the COVID-19 pandemic, homeless individuals may represent a particularly important group to study. ${ }^{4}$ They have recently been identified as 
potential "super spreaders" since they are characterized by a high geographic mobility and transience. ${ }^{4}$ Therefore, it has been argued that it is difficult to track and prevent transmission. ${ }^{4}$ Moreover, once getting infected with COVID-19, they may show a greater resistance to required hospital admission, which can make the care process more difficult. $^{5}$ Furthermore, isolation and quarantine may be difficult for homeless individuals. In conclusion, knowledge about this group is of highest importance during the COVID-19 pandemic.

In our current study, we were interested in fear of COVID-19 among homeless individuals during this pandemic. Reporting fear of COVID-19 appears to be plausible, mainly since individuals are worried about their health. ${ }^{6}$ Such a fear has often been reported during this pandemic among different groups. ${ }^{7}$ Due to the poor hygienic conditions ${ }^{8}$ and their increased vulnerability, ${ }^{9,10}$ it particularly appears plausible that homeless individuals report an increased fear of COVID-19.

Knowledge about fear of COVID-19 is important because careful actions, particularly among homeless, are required in these times. ${ }^{11}$ While we think that low levels of fear of COVID-19 among homeless can contribute to a careless behavior and can ultimately result in superspreading events, very high levels of fear of COVID-19 among homeless can have mental health consequences. ${ }^{12}$ Furthermore, an increased fear (and therefore not thinking clearly) may result in suicide. ${ }^{13}$ Therefore, a rational assessment of COVID-19, its transmission route, how to prevent it spreading and its consequences is supposed to be important among homeless individuals.

Previous studies have shown some correlates of fear of COVID-19. For instance, recent studies showed that an increased fear of COVID-19 is associated with being female $^{14}$ or socially vulnerable groups. ${ }^{12}$ However, the existing studies mainly focused on samples other than homeless individuals (such as samples derived from the general population ${ }^{12,15}$ or university students ${ }^{16,17}$ ). To the best of our knowledge, there is a complete lack of studies focusing on the fear of COVID-19 among homeless individuals during the pandemic. Thus, our purpose was to fill this gap in knowledge.

\section{Patients and Methods}

\section{Sample}

For the current study, cross-sectional data were used from the recently conducted Hamburg survey of homeless individuals (25th May to 3rd June 2020). Homeless adults were interviewed in night shelters, specialized medical practices or lodging houses. Only three out of 154 potential participants refused the participation leading to a response rate of about $98 \%$. Due to missing data, the final analytical sample was composed of 150 individuals.

Individuals were interviewed and examined in a separate room (covering, among other things, demographic data, and a questionnaire-based interview). Given the ability to read and understand the questions, the participants could fill out the questionnaire on their own. Most questionnaires were filled out by means of face-to-face interviews due to difficulties in reading and understanding the questions. Prior to investigation, all individuals gave their written informed consent. The study was conducted in accordance with the Declaration of Helsinki, and the ethical statement was obtained from the medical council of Hamburg (application number: PV7333).

\section{Dependent Variables}

Individuals were asked: How concerned are you about contracting COVID-19 one day? $[1=$ Not at all; $2=$ a little; $3=$ somewhat; $4=$ severely?]. This is a common way to assess, eg, fear of dementia and was also used in similar studies. ${ }^{18,19}$

\section{Independent Variables}

Based on theoretical considerations and based on previous studies (e.g., ${ }^{14,20}$ ), we included as explanatory variables: age, sex (women; men), individual history of homelessness (ie, time of homelessness in months), family status (married; single; widowed; divorced), country of origin (Germany; neighboring country; other country), educational level (CASMIN classification (Comparative Analysis of Social Mobility in Industrial Nations), distinguishing between primary, secondary and tertiary education ${ }^{21}$ ). Furthermore, the presence of chronic alcohol consume ${ }^{22,23}$ (defined by carbohydrate-deficient transferrin $(\mathrm{CDT})>2.5$ ) was used.

Furthermore, COVID-19-related variables were included in the regression model:

- How do you estimate your risk of contracting COVID-19 one day? ( $1=$ very low, $2=$ low, $3=$ average, $4=$ increased or $5=$ high $)$

Additionally, individuals were asked to what extent they agree with these statements (ranging from $1=$ does not apply at all to $7=$ fully applies): 
- There is quite a lot of what I can do by myself to avoid contracting COVID-19.

- The diagnosis of coronavirus disease (COVID-19) would ruin my life.

\section{Statistical Analysis}

First, sample characteristics (for our analytical sample with $n=150$ ) are shown. Descriptive statistics are given as mean and standard deviation for continuous variables and frequency and percentage (\%) for categorical variables. Afterwards, factors associated with fear of COVID-19 were investigated using multiple linear regression models. Furthermore, to deal with missing data, full information maximum likelihood was used in a further analysis. $^{24,25}$ In another sensitivity analysis, linear regression models were replaced by ordered probit regression models to take into consideration the potential ordinal nature of the dependent variable. The significance level was set at 0.05 and Stata 16.0 (Stata Corp., College Station, Texas) was used to perform statistical analysis.

\section{Results}

\section{Sample Characteristics}

The sample characteristics $(\mathrm{n}=150)$ for the total sample are shown in Table 1. The average age was 44.6 years (SD: 12.5 years, 19 to 86 years), and most individuals were male $(80.5 \%)$. In sum, $56.2 \%$ reported no fear of COVID$19,23.8 \%$ reported a little fear of COVID-19, 9.2\% reported some fear of COVID-19, and 10.8\% reported severe fear of COVID-19. The average score for fear of COVID-19 was 1.7 (SD: 1.0). Further details are given in Table 1.

\section{Regression Analysis}

The findings of multiple linear regressions with fear of COVID-19 as outcome measure are displayed in Table 2 (second column: multiple linear regressions were used and listwise deletion was used to handle missing values). $\mathrm{R}^{2}$ equaled 0.47. Regressions revealed that an increased fear of COVID-19 was significantly associated with younger age $(\beta=-.01, p<0.05)$, absence of chronic alcohol consume $(\beta=-.55, p<0.01)$, an increased perceived own risk of contracting COVID-19 one day $(\beta=0.42, p<0.001)$ and a higher agreement that a diagnosis of the coronavirus disease would ruin his/her life $(\beta=0.13, p<0.01)$.

In further analysis, multiple linear regressions with full-information maximum likelihood (to address the issue of missing values) were performed (third column: multiple linear regressions were used and full information maximum likelihood was used to handle missing values). In terms of effect sizes and significance, results remained nearly the same (see last column, Table 2). In supplementary file 1 (including Supplementary Table 1 and Supplementary Table 2), the aforementioned regression models are described in further detail (additionally including standardized regression coefficients and 95\% CI).

In sensitivity analysis, multiple linear regressions were replaced using ordered probit regressions (results not shown, but available upon request). In terms of significance, findings remained virtually the same.

\section{Discussion}

Using rare data of homeless individuals during the COVID19 pandemic, our study adds first knowledge to the prevalence and determinants of fear of COVID-19 in this group. Our study showed that while $80 \%$ of the homeless individuals reported no/a little fear of COVID-19, the remaining $20 \%$ of the individuals reported some/severe fear of COVID19. Regressions revealed that an increased fear of COVID19 is significantly associated with younger age, absence of chronic alcohol consume, an increased perceived own risk of contracting COVID-19 one day and a higher agreement that a diagnosis of the coronavirus disease would ruin his/her life.

Given the vulnerability (eg, in terms of multimorbidity) of homeless individuals, the rather low prevalence of fear of COVID-19 (80\% reporting no/a little fear) - even compared to other populations in other countries ${ }^{12,15}$ - is noteworthy. Because it has been shown that women reported increased fear of COVID-19 scores, ${ }^{26}$ we assume that the low prevalence rate can be - at least partly explained by the low proportion of female homeless individuals in our sample. In our study, women tended to have higher fear scores. However, probably due to a lack of statistical power, gender differences were not statistically significant. Furthermore, homeless individuals may neglect the risks of being infected with SARS-CoV-2 (eg, due to psychiatric illnesses).

Given the probable more severe health consequences of SARS-CoV-2 infection, at first glance it seems counterintuitive that age is negatively associated with fear of COVID-19 among older homeless individuals. However, we assume that the geographic mobility is increased among younger homeless individuals - which may be associated with a higher perceived risk of being infected. Therefore, they may report an increased fear of COVID- 
Table I Sample Characteristics for the Total Sample $(n=150)$

\begin{tabular}{|c|c|}
\hline Variables & $\begin{array}{l}\text { Mean (Standard Deviation)/N } \\
\text { (\%) }\end{array}$ \\
\hline \multicolumn{2}{|l|}{ Gender } \\
\hline Male & $120(80.5 \%)$ \\
\hline Female & $29(19.5 \%)$ \\
\hline Age & $44.6(12.5)$ \\
\hline \multicolumn{2}{|l|}{ Family status } \\
\hline Single & $89(68.5 \%)$ \\
\hline Widowed/Divorced/Married, living separated from spouse & $4 \mathrm{I}(3 \mathrm{I} .5 \%)$ \\
\hline \multicolumn{2}{|l|}{ Education } \\
\hline Primary education & $42(32.6 \%)$ \\
\hline Secondary/tertiary education & $87(67.4 \%)$ \\
\hline \multicolumn{2}{|l|}{ Country of origin } \\
\hline Germany & $64(45.7 \%)$ \\
\hline Neighboring country & $40(28.6 \%)$ \\
\hline Other country & $36(25.7 \%)$ \\
\hline \multicolumn{2}{|l|}{ Alcohol consume } \\
\hline Absence of chronic alcohol consume (CDT $\leq 2.5)$ & $88(62.0 \%)$ \\
\hline Presence of chronic alcohol consume (CDT > 2.5) & $54(38.0 \%)$ \\
\hline Fear of COVID-I9 (from I = not at all to $4=$ severely) & $1.7(1.0)$ \\
\hline Not at all & $73(56.2 \%)$ \\
\hline A little & $31(23.8 \%)$ \\
\hline Somewhat & $12(9.2 \%)$ \\
\hline Severely & $14(10.8 \%)$ \\
\hline Perceived own risk of getting the coronavirus one day (from I $=$ very low to $5=$ high) & $2.1(1.1)$ \\
\hline Very low & $54(42.9 \%)$ \\
\hline Low & $26(20.6 \%)$ \\
\hline Average & $32(25.4 \%)$ \\
\hline Increased & $10(7.9 \%)$ \\
\hline High & $4(3.2 \%)$ \\
\hline $\begin{array}{l}\text { Perception that being infected with the coronavirus is preventable (from I = does not apply to } 7=\text { fully } \\
\text { applies) }\end{array}$ & $4.9(2.1)$ \\
\hline $\begin{array}{l}\text { Agreement that a diagnosis of the coronavirus would ruin his/her life (from I = does not apply to } 7=\text { fully } \\
\text { applies) }\end{array}$ & $3.1(2.3)$ \\
\hline
\end{tabular}

Notes: Descriptive statistics were given as mean and standard deviation for continuous variables and frequency and percentage (\%) for categorical variables.

19. Previous research in other countries (and non-homeless samples) showed conflicting results regarding the link between age and fear of COVID-19. ${ }^{27-31}$ Thus, future research is required to clarify the link between age and fear of COVID-19.

Previous research has demonstrated a link between short-term drinking alcohol and increased fear of COVID-19 in medical students in Vietnam. ${ }^{17}$ Similar results were found among Russian and Belarusian university students. ${ }^{16}$ However, these previous findings based on student samples and focusing on short-term alcohol consumption are difficult to compare to our findings based on homeless individuals and focusing on chronic alcohol consume. We assume that homeless individuals with a chronic alcohol consume may systematically underestimate or misjudge the risks and consequences of COVID-19 and may therefore report a low fear of COVID-19 in our study. In the same vein, it has been 
Table 2 Determinants of Fear of COVID-19. Findings of Multiple Linear Regressions (Second Column: With Listwise Deletion, $\mathrm{n}=10 \mathrm{O}$; Third Column: With Full-Information Maximum Likelihood, $n=150$ )

\begin{tabular}{|c|c|c|}
\hline Independent Variables & $\begin{array}{l}\text { Fear of COVID-I } 9 \text { (Using } \\
\text { Listwise Deletion) }\end{array}$ & $\begin{array}{l}\text { Fear of COVID-I9 (Using Full- } \\
\text { Information Maximum Likelihood) }\end{array}$ \\
\hline Gender: - Female (Ref.: Male) & $0.18(0.22)$ & $0.22(0.18)$ \\
\hline Age & $-0.01 *(0.01)$ & $-0.01 *(0.01)$ \\
\hline $\begin{array}{l}\text { Family status: - Widowed/Divorced/Married, living separated from } \\
\text { spouse (Ref.: Single) }\end{array}$ & $0.07(0.18)$ & $-0.00(0.16)$ \\
\hline Education: - Secondary/tertiary education (Ref.: Primary education) & $0.12(0.17)$ & $0.16(0.14)$ \\
\hline Country of origin: - Neighboring country (Germany) & $0.18(0.24)$ & $0.33+(0.20)$ \\
\hline - Other country & $-0.15(0.18)$ & $-0.14(0.17)$ \\
\hline $\begin{array}{l}\text { Alcohol consume: - Presence of chronic alcohol consume (CDT > } \\
\text { 2.5) (Ref.: Absence of chronic alcohol consume) }\end{array}$ & $-0.55 * *(0.17)$ & $-0.51 * *(0.17)$ \\
\hline $\begin{array}{l}\text { Perceived own risk of getting the coronavirus one day (from I = } \\
\text { very low to } 5=\text { high) }\end{array}$ & $0.42^{* * *}(0.08)$ & $0.46^{* * *}(0.07)$ \\
\hline $\begin{array}{l}\text { Perception that being infected with the coronavirus is preventable } \\
\text { (from I = does not apply to } 7 \text { = fully applies) }\end{array}$ & $-0.01(0.05)$ & $-0.02(0.04)$ \\
\hline $\begin{array}{l}\text { Agreement that a diagnosis of the coronavirus would ruin his/her life } \\
\text { (from I = does not apply to } 7 \text { = fully applies) }\end{array}$ & $0.13^{* *}(0.04)$ & $0.12^{* * *}(0.03)$ \\
\hline Constant & $0.34(0.42)$ & $0.24(0.37)$ \\
\hline Observations & 101 & 150 \\
\hline $\mathrm{R}^{2}$ & 0.47 & 0.47 \\
\hline
\end{tabular}

Notes: Unstandardized beta-coefficients are reported; robust standard errors in parentheses; $*_{* *} p<0.00 \mathrm{I},{ }^{*} *_{p}<0.01,{ }^{*} p<0.05,+p<0.10$.

shown that alcohol addicts overestimate their invulnerability and tend to fatalism. ${ }^{32}$

In accordance with previous research showing an association between risk perception and fear of other illnesses such as dementia or cancer, ${ }^{33,34}$ we showed that the perceived risk of contracting COVID-19 one day is positively associated with the fear of COVID-19. Therefore, it is plausible that these factors are also associated in our study.

The importance of consequences of illnesses for fear assessment has also been stressed in former research. Such a link has also been demonstrated in cancer and dementia research. ${ }^{33,35}$ Therefore, in our study, homeless individuals reported an increased fear of COVID-19 when this disease has perceived negative consequences for them - which appears to be very plausible.

Several strengths and limitations of our study are worth describing. We used rare data from a particularly vulnerable population (homeless individuals) which is usually difficult to reach. Moreover, interviews were conducted during the COVID-19 pandemic. The response rate in the Hamburg survey of homeless individuals was very high (98\%). To the best of our knowledge, this is the first study assessing the prevalence and investigating the determinants of fear of COVID-19 among homeless individuals during the COVID-19 pandemic. Moreover, another strength of this study is that other COVID-19-related questions were included (perceived risk of contracting COVID19; consequences of COVID-19 diagnosis for own life; perceived modifiability of getting infected with SARS$\mathrm{CoV}-2)$ in our analysis.

Similar single-item measures were used to measure fear of COVID-19 in previous research ${ }^{12}$ and also in assessing fear of other illnesses such as dementia in other large cohort studies. ${ }^{18,36,37}$ Furthermore, we used such a tool due to the vulnerability of this specific group, which generally requires the use of ultrashort tools to avoid misunderstandings and item non-response. ${ }^{2}$ Moreover, our outcome measure showed a high face validity. Nevertheless, it should be 
noted that initially validated COVID-19 scales have been developed in the year 2020 such as the tool conducted by Ahorsu et $\mathrm{al}^{38}$. Moreover, since some missing data were present in the Hamburg survey of homeless individuals, we checked the robustness of our results by using ordered probit models and linear regression models with full information maximum likelihood (FIML) for dealing with missing data. $^{24,25}$ The additional models produced nearly identical results. Furthermore, it should be emphasized that this is a cross-sectional study with its inherent limitations regarding causality.

\section{Conclusion}

Given the poor hygienic conditions and their increased vulnerability, data surprisingly suggest a quite low fear of COVID-19 among homeless individuals. Efforts may be beneficial which contribute to thinking rationally about COVID-19 among homeless people, since low levels of fear of COVID-19 may contribute to careless behavior and can lead to super-spreading events.

\section{Abbreviations}

BAGW, Federal Association for Assistance to Homeless People; CASMIN, Comparative Analysis of Social Mobility in Industrial Nations; CDT, carbohydrate-deficient transferrin; COVID-19, coronavirus disease 2019; FIML, full information maximum likelihood; HIV, human immunodeficiency virus; Ref, reference category; $\mathrm{R}^{2}$, coefficient of determination; SARS-CoV-2, severe acute respiratory syndrome coronavirus type 2 ; SD, standard deviation.

\section{Data Sharing Statement}

The datasets analysed during the current study are not publicly available due to ethical restrictions involving patient data but are available from the corresponding author on reasonable request.

\section{Ethics Approval and Informed Consent}

Prior to investigation, all individuals gave their written informed consent. The study was conducted in accordance with the Declaration of Helsinki, and the ethical statement was obtained from the medical council of Hamburg (application number: PV7333).

\section{Consent for Publication}

Not applicable.

\section{Author Contributions}

All authors made a significant contribution to the work reported, whether that is in the conception, study design, execution, acquisition of data, analysis and interpretation, or in all these areas; took part in drafting, revising or critically reviewing the article; gave final approval of the version to be published; have agreed on the journal to which the article has been submitted; and agree to be accountable for all aspects of the work.

\section{Funding}

The study was made financially possible by uncommitted private donations to the University Medical Centre Hamburg-Eppendorf. The funders had no role in study design, data collection and analysis, decision to publish, or preparation of the manuscript.

\section{Disclosure}

The authors report no conflicts of interest in this work.

\section{References}

1. Federal Association for Assistance to Homeless People (BAGW). Zahl der Wohnungslosen [Number of homeless individuals]: Federal Association for Assistance to Homeless People (BAGW); 2019. p. 1-4.

2. Ratzka M, Kämper A Befragung obdachloser, auf der Straße lebender Menschen und wohnungsloser, öffentlichrechtlich untergebrachter Haushalte 2018 in Hamburg. Auswertungsbericht. Bielefeld: GOE Bielefeld; 2018.

3. Fazel S, Geddes JR, Kushel M. The health of homeless people in high-income countries: descriptive epidemiology, health consequences, and clinical and policy recommendations. Lancet. 2014;384(9953):1529-1540. doi:10.1016/S0140-6736(14)61132-6

4. Tsai J, Wilson M. COVID-19: a potential public health problem for homeless populations. Lancet Public Health. 2020;5(4):e186-e187. doi:10.1016/S2468-2667(20)30053-0

5. Kar SK, Arafat SY, Marthoenis M, Kabir R. Homeless mentally ill people and COVID-19 pandemic: the two-way sword for LMICs. Asian J Psychiatr. 2020;51:102067. doi:10.1016/j.ajp.2020.102067

6. Read S, Comas-Herrera A, Grundy E. Social Isolation and memory decline in later-life. J Gerontol. 2020;75(2):367-376. doi:10.1093/ geronb/gbz152

7. Wang C, Pan R, Wan X, et al. Immediate psychological responses and associated factors during the initial stage of the 2019 coronavirus disease (COVID-19) epidemic among the general population in China. Int $J$ Environ Res Public Health. 2020;17(5):1729. doi:10.3390/ijerph17051729

8. Perri M, Dosani N, Hwang SW. COVID-19 and people experiencing homelessness: challenges and mitigation strategies. CMAJ. 2020;192 (26):E716-E719. doi:10.1503/cmaj.200834

9. Lima NNR, de Souza RI, Feitosa PWG, de Sousa Moreira JL, da Silva CGL, Neto MLR. People experiencing homelessness: their potential exposure to COVID-19. Psychiatry Res. 2020;112945. doi:10.1016/j.psychres.2020.112945

10. Wood L, Davies A, Khan Z. COVID-19 precautions-easier said than done when patients are homeless. Med J Aust. 2020;1. doi:10.5694/ mja2.50571 
11. Pakpour AH, Griffiths MD. The fear of COVID-19 and its role in preventive behaviors. J Concurrent Disorders. 2020.

12. Fitzpatrick KM, Harris C, Drawve G. Fear of COVID-19 and the mental health consequences in America. Psychol Trauma. 2020;12 (S1):S17-S21. doi:10.1037/tra0000924

13. Fitzpatrick KM, Harris C, Drawve G. How bad is it? Suicidality in the middle of the COVID-19 pandemic. Suicide Life-Threatening Behavi. 2020;50:1241-1249. doi:10.1111/sltb.12655

14. Broche-Pérez Y, Fernández-Fleites Z, Jiménez-Puig E, FernándezCastillo E, Rodríguez-Martin BC. Gender and Fear of COVID-19 in a Cuban Population Sample. Int J Ment Health Addict. 2020;1-9.

15. Doshi D, Karunakar P, Sukhabogi JR, Prasanna JS, Mahajan SV. Assessing coronavirus fear in Indian population using the feAR of COVID-19 Scale. Int J Ment Health Addict. 2020;1. doi:10.1007/ s11469-020-00332-x

16. Gritsenko V, Skugarevsky O, Konstantinov V, et al. COVID 19 fear, stress, anxiety, and substance use among Russian and Belarusian university students. Int J Ment Health Addict. 2020;1.

17. Nguyen HT, Do BN, Pham KM, et al. Fear of COVID-19 scaleassociations of its scores with health literacy and health-related behaviors among medical students. Int $J$ Environ Res Public Health. 2020;17(11):4164. doi:10.3390/ijerph17114164

18. Cantegreil-Kallen I, Pin S. Fear of Alzheimer's disease in the French population: impact of age and proximity to the disease. Int Psychogeriatr. 2012;24(1):108-116. doi:10.1017 S1041610211001529

19. Norman AL, Woodard JL, Calamari JE, et al. The fear of Alzheimer's disease: mediating effects of anxiety on subjective memory complaints. Aging Ment Health. 2018;1-7.

20. Mertens G, Gerritsen L, Duijndam S, Salemink E, Engelhard IM. Fear of the coronavirus (COVID-19): predictors in an online study conducted in March 2020. J Anxiety Disord. 2020;74:102258. doi:10.1016/j.janxdis.2020.102258

21. Brauns H, Steinmann S. Educational reform in France, West-Germany and the United Kingdom: updating the CASMIN educational classification. Zuma Nachrichten. 1999;23(44):7-44.

22. Bortolotti F, Sorio D, Bertaso A, Tagliaro F. Analytical and diagnostic aspects of carbohydrate deficient transferrin (CDT): a critical review over years 2007-2017. J Pharm Biomed Anal. 2018;147:2-12. doi:10.1016/j.jpba.2017.09.006

23. Stibler H. Carbohydrate-deficient transferrin in serum: a new marker of potentially harmful alcohol consumption reviewed. Clin Chem. 1991;37(12):2029-2037. doi:10.1093/clinchem/37.12.2029

24. Allison PD Handling missing data by maximum likelihood. Paper presented at: SAS global forum; 2012.

25. Von Hippel PT. New confidence intervals and bias comparisons show that maximum likelihood can beat multiple imputation in small samples. Structural Equ Model. 2016;23(3):422-437. doi:10.1080/ 10705511.2015.1047931
26. Andrade EF, Pereira LJ, Oliveira A. et al. Perceived fear of COVID-19 infection according to sex, age and occupational risk using the Brazilian version of the Fear of COVID-19 Scale. Death Stud;2020. 1-10. doi: 10.1080/07481187.2020.1809786

27. Chen Q, Zhang J, Xu Y, Sun H, Ding Z. Associations between individual perceptions of PM 2.5 pollution and pulmonary function in Chinese middle-aged and elderly residents. BMC Public Health. 2020;20(1):1-9. doi:10.1186/s12889-020-08713-6

28. de Leo D, Trabucchi M. COVID-19 and the fears of Italian senior citizens. Int $J$ Environ Res Public Health. 2020;17(10):3572. doi:10.3390/ijerph17103572

29. Haktanir A, Seki T, Dilmaç B. Adaptation and evaluation of Turkish version of the fear of COVID-19 scale. Death Stud. 2020;1-9. doi:10.1080/07481187.2020.1773026

30. Meng H, Xu Y, Dai J, Zhang Y, Liu B, Yang H. Analyze the psychological impact of COVID-19 among the elderly population in China and make corresponding suggestions. Psychiatry Res. 2020;289:112983. doi:10.1016/j.psychres.2020.112983

31. Soraci P, Ferrari A, Abbiati FA. et al. Validation and psychometric evaluation of the Italian version of the Fear of COVID-19 Scale. Int J Ment Health Addict;2020. 1-10. doi: 10.1007/s11469-02000277-1

32. Perloff LS. Social comparison and illusions of invulnerability to negative life events. In: Coping with Negative Life Events. Springer; 1987:217-242.

33. Hajek A, König H. Fear of dementia in the general population: findings from the German Socio-Economic Panel (GSOEP). J Alzheimer's Dis. 2020;75(4):1135-1140.

34. Kwak MS, Choi KS, Park S, Park EC. Perceived risk for gastric cancer among the general Korean population: a population-based survey. Psycho-Oncol. 2009;18(7):708-715. doi:10.1002/pon.1458

35. Vickberg SMJ. The Concerns About Recurrence Scale (CARS): a systematic measure of women's fears about the possibility of breast cancer recurrence. Ann Behav Med. 2003;25(1):16-24. doi:10.1207/ S15324796ABM2501_03

36. Hajek A, König -H-H. Fear of dementia in the general population: findings from the German Socio-Economic Panel (GSOEP). J Alzheimer's Dis. 2020;75(4):1135-1140. doi:10.3233/JAD-200106

37. Norman AL, Woodard JL, Calamari JE, et al. The fear of Alzheimer's disease: mediating effects of anxiety on subjective memory complaints. Aging Ment Health. 2020;24(2):308-314. doi:10.1080/ 13607863.2018.1534081

38. Ahorsu DK, Lin C-Y, Imani V, Saffari M, Griffiths MD, Pakpour AH. The fear of COVID-19 scale: development and initial validation. Int J Ment Health Addict. 2020. doi:10.1007/s11469-020-00270-8
Risk Management and Healthcare Policy

\section{Publish your work in this journal}

Risk Management and Healthcare Policy is an international, peerreviewed, open access journal focusing on all aspects of public health, policy, and preventative measures to promote good health and improve morbidity and mortality in the population. The journal welcomes submitted papers covering original research, basic science, clinical \& epidemiological studies, reviews and evaluations, guidelines, expert opinion and commentary, case reports and extended reports. The manuscript management system is completely online and includes a very quick and fair peer-review system, which is all easy to use. Visit http://www.dovepress.com/testimonials.php to read real quotes from published authors. 